\title{
Determination of residual parachloroaniline produced by endodontic treatment after the use of $5 \%$ sodium hypochlorite and $2 \%$ chlorhexidine combined: an ex-vivo study
}

\author{
O Alegre ${ }^{1}$, I Yévenes ${ }^{1}$, J Parada ${ }^{1}$, S Maggiolo², E Fernández ${ }^{3^{*}}$
}

\begin{abstract}
1. Institute of Basic Sciences - Faculty of Dentistry University of Chile. - Santiago, Chile.

2. Department of Conservative Dentistry - Faculty of Dentistry - University of Chile. - Santiago, Chile. 3. Department of Restorative Dentistry - Faculty of Dentistry - University of Chile. - Santiago, Chile.

* Corresponding author. Eduardo Fernández G. DDS, DS, PhD | Department of Restorative Dentistry | Universidad de Chile, Dental school | Sergio Livingstone Pohlhammer 943, Independencia |Email:edofdez@yahoo.com | Phone-Fax:+56229462929| Santiago, Chile. Trabajo recibido el 16/01/2017. Aprobado para su publicación el 14/08/2017
\end{abstract}

\begin{abstract}
Aim: The objective of this work was to determine the concentrations of irrigating solutions and the residual content of parachloroaniline (PCA) formed after endodontic irrigation, using $5 \% \mathrm{NaOCl}, 0.9 \% \mathrm{NaCl}, 10 \%$ EDTA and $2 \% \mathrm{CHX} 2 \%$. Methodology Twenty premolars were used and 13 samples were collected per tooth from each of the treatment phases. Samples of: $\mathrm{NaOCl}$, EDTA, CHX and PCA were quantified by UV and visible spectrophotometry.

Results: Sodium hypochlorite decreased its concentration from $3.8 \%$ to $3.4 \%$ in phases 1 to 4 . In phases 5, 6 and 7 , residual $\mathrm{NaOCl}$ was measured with concentrations of $0.007 \%, 0.003 \%$ and $0.001 \% \%$. The concentration of EDTA decreased to $8.85 \%$ in phase 8 . In phases 9,10 and 11 , irrigated with serum, EDTA was quantified with concentrations of $0.013 \%$ to $0.002 \%$ and $\mathrm{NaOCl}$ values of $0.0011 \%$ to $0,0006 \%$. In phases 12 and $13, \mathrm{CHX}$ concentrations were $1.850 \%$ and $1.812 \%$ and $\mathrm{PCA}$ values were $0.0005 \%$ and $0.0007 \%$. PCA formation occurred in presence of $2 \% \mathrm{CHX}$ and residual $\mathrm{NaClO}$ and was detected colorimetrically in phases 12 and 13 .

Conclusions. During endodontic irrigation the concentration of $5 \% \mathrm{NaOCl}$ decreases significantly in the first four phases and the concentrations of EDTA and CHX also decrease. There is PCA training in the last stages of the procedure.

KEY WORDS
\end{abstract}

Parachloroaniline, Endodontic Irrigation, Chlorhexidine, Sodium Hypochlorite, EDTA.

Rev. Clin. Periodoncia Implantol. Rehabil. Oral Vol. 10(3); 145-148, 2017.

\section{INTRODUCTION}

The success of endodontic treatment is established when disinfection and three-dimensional sealing root canal systems (RCS) are achieved, thus preventing reinfection. The complex anatomy of the RCS prevents the microorganisms and residual organic and inorganic tissue from being fully eliminated through the single use of instrumentation, so the use of different substances for irrigation is necessary ${ }^{(1)}$.

None of the available irrigating solutions can be regarded as optimal. Using a combination of two or more solutions in the correct irrigating sequence and in a specific concentration contributes to a successfu treatment outcome ${ }^{(2)}$. Overall, an irrigating solution is not completely removed from the RCS before applying the next one; and as a result, contact into the root canal may form byproducts, which may occlude dentinal tubules, affecting the sealing of the RCS or which are even toxic to the periapical tissues.

Sodium hypochlorite $(\mathrm{NaOCl})$ is used in endodontics because of its high antimicrobial activity and capability to dissolve organic and necrotic tissue ${ }^{(3)}$. These properties are directly proportional to the concentration in the solution. For acceptable levels of cytotoxicity against bacteria, a concentration of $0.5 \%$ is recommended, but this requires at least 30 minutes of action to inhibit the growth of facultative microorganisms in vitro. In contrast, $5.25 \% \mathrm{NaOCl}$ eliminates microorganisms in vitro in a few seconds ${ }^{(4,5)}$.

Currently, there is no single irrigant that can eliminate the smear layer formed by the instrumentation, so the sequential use of $\mathrm{NaOCl}$ and EDTA, a chelating agent to dissolve inorganic tissue, is needed, causing decalcification of peri and intertubular dentin, because it has the chemical characteristic of binding to di or trivalent metals such as $\mathrm{Ca}^{2+}$ and $\mathrm{Fe}^{3+(6)}$.

$\mathrm{CHX}$ is used as another irrigant solution; it has a broad spectrum of action on Gram-positive and Gram-negative bacteria. However, it is not capable of dissolving organic tissues and therefore cannot replace $\mathrm{NaOCl}$ as an irrigant of choice, but it is useful as an adjunct agent for endodontic treatment at $2 \%$ concentration, as an irrigant or medication, due to its substantivity and broad antibacterial spectrum ${ }^{(1)}$.
Because $2 \% \mathrm{CHX}$ solution is not capable of dissolving organic tissues, efforts have been made to combine it with $\mathrm{NaOCl}$ and obtain the benefits of both substances. However, these are not soluble with each other, when mixed a brown-orange precipitate appeared. Its characteristics have not been fully examined, but its formation does not allow the clinical use of the mixture of these two solutions ${ }^{(7,8)}$.

In the precipitate formed by the interaction between $\mathrm{CHX}$ and $\mathrm{NaOCl}$, various authors have indicated the presence of a substance called Parachloroaniline, 1-amine-4-chlorobenzene, p-chloroaniline or PCA. The amount of precipitate formed is directly related to the concentration of $\mathrm{NaOCl}, 0.023 \%$ being the lowest concentration at which discoloration of the combined solutions was observed and $0.19 \%$, the minimum at which a precipitate is formed ${ }^{(7)}$.

The World Health Organization (WHO) and the International Agency for Research on Cancer (IACR) categorize parachloroaniline in Group 2B, which means that this agent is potentially carcinogenic to humans ${ }^{(9)}$. PCA is a toxic compound and only considering the non-neoplastic effects, such as methemoglobinemia, the maximum tolerable level of human exposure is on the order of $2 \mu \mathrm{g} / \mathrm{kg} /$ day. Accidental acute exposure to PCA in high concentrations can be deadly $y^{(9)}$. At present, there are no studies that show the effects that PCA could produce and the amount of residual precipitate has not been determined.

Therefore, the aim of this work was to determine the concentration of the irrigating solutions and the amount of residual content of PCA formed after using an irrigation protocol, that use $5 \% \mathrm{NaOCl}, 0,9 \% \mathrm{NaCl}, 10 \%$ EDTA and $2 \% \mathrm{CHX}$.

\section{METHODOLOGY}

An ex vivo model of 20 single-rooted teeth, extracted by therapeutic indication, was mounted. These were cleaned, debrided and stored in $0.9 \% \mathrm{NaCl}$ (J.T.Baker, Mallinckrodt Baker, S.A. de C.V. Xalostoc, 55320, Edo de Mex. Mexico, Made in USA printed in Mexico). Each of the 20 teeth of the sample underwent endodontic treatment using the specific irrigation protocol proposed. 


\section{IRRIGATION PROTOCOL}

Phase 1(F1): Communication with the canal and immediate Irrigation with $5 \% \mathrm{NaOCl}$ (Sigma-Aldrich 3050 Spruce St. St. Louis, MO 63103 USA) (3mL) and collection of sample.

Phase 2(F2): Preparation of the cervical and middle third with Gates Glidden Drills, irrigation with $5 \% \mathrm{NaOCl}(3 \mathrm{~mL})$ and collection of sample.

Phase 3(F3): Preparation of the apical third with Endodontic K-files (SybronEndo Corporation, 1717 West Collins, Orange, CA 92867 USA). Irrigation with $5 \% \mathrm{NaOCl}(3 \mathrm{~mL})$ and collection.

Phase 4(F4): Step Back instrumentation with K-files, irrigation with 5\% $\mathrm{NaOCl}(3 \mathrm{~mL})$ and collection. Canal was dried with sterile paper cones.

Phase 5(F5), phase 6(F6) and phase 7(F7): Irrigation with $0.9 \% \mathrm{NaCl}$ ( $3 \mathrm{~mL}$ each one) and collection of each samples. Then canal was dried with sterile paper cones.

Phase 8(F8): Irrigation with 10\% EDTA (Merck Millipore, Frankfurter Str. 250, 64293 Darmstadt, Germany) and collection of sample.

Phase 9(F9), phase 10(F10) and phase 11(F11): Irrigation with $0.9 \%$ $\mathrm{NaCl}(3 \mathrm{~mL}$ each one) and collection of each samples. Then canal was dried with sterile paper cones.

Phase 12(F12): Irrigation with 2\% CHX (Chlorhexidine digluconate solution 20\% in H2O, Sigma-Aldrich 3050 Spruce St. St. Louis, MO 63103 USA) (3mL) and collection.

Next, the tooth was double sealed with Fermin Detax (DETAX GmbH \& Co. KG, Carl-Zeiss-Str. 476275 Ettlingen, Germany) and self-curing glass ionomer, apex was sealed with wax and set on a saline vial in an oven at $37^{\circ} \mathrm{C}$ for one week (usual time of intracanal medication). After this time, the temporary sealing was removed.

Phase 13(F13): the canal was washed with $3 \mathrm{~mL}$ of $2 \% \mathrm{CHX}$ and the last collection was performed.

The different solutions produced during irrigation were collected using a Monoject aspiration syringe (Covidien lic, 15 Hampshire, Mansfield, MA 02048 USA), kept in sealed containers and labeled to be analyzed in the laboratory.

\section{LABORATORY PROCEDURES}

Samples of each phase were transferred to Eppendorf $(1.5 \mathrm{ml})$ tubes (Biologix Group Limited, No.2766 Ying XiuRoad,High-Tech Industria Development Zone Jinan, Shandong 250101 P.R. China), centrifuged at $10,000 \mathrm{rpm}$ for 5 minutes and the absorption spectrum was registered in the UV-visible range $(200-800 \mathrm{~nm})$ in a spectrophotometer UNICAM ${ }^{\circledR} U V$ VIS (ThermoSpectronicUnicam UV-530 UV-Visible, Rochester, NY, USA), using a quartz cuvette. Dilution series from standard to initial concentration ( $5 \% \mathrm{NaClO}, 10 \%$ EDTA y $2 \% \mathrm{CHX}$ ) were prepared. We determined the $\lambda$ max and built a calibration curve for each one (Table 1), which was used to establish the concentration in the samples collected.

To determine the concentration of PCA in the samples, a modified protocol described in the European Pharmacopoeia $(2005)^{(10)}$ was applied to detect presence of p-chloroaniline in chlorhexidine gluconate solutions. We added $250 \mu \mathrm{L}$ diluted $(73 \mathrm{~g} / \mathrm{L})$ hydrochloric acid (J.T.Baker, Mallinckrodt Baker, S.A. de C.V. Xalostoc, 55320, Edo de Mex. Mexico, Made in USA printed in Mexico to the $1 \mathrm{~mL}$ sample and diluted to $2 \mathrm{~mL}$ with distilled water. The following solutions were added rapidly, stirring after each addition: $36 \mu \mathrm{L}$ of Sodium Nitrite (100g/L) (Merck Millipore, Frankfurter Str. 250, 64293 Darmstadt, Germany); $200 \mu \mathrm{L}$ Ammonium Sulfamate (50g/L) (Sigma-Aldrich ChemieGmbh Munich, Germany); $500 \mu \mathrm{L}$ (N-1-Naphthyl) ethylenediaminedihydrochloride (1g/L) (SigmaAldrich 3050 Spruce St. St. Louis, MO 63103 USA); $100 \mu \mathrm{L}$ Ethanol 96\% (Merck Millipore, Frankfurter Str. 250, 64293 Darmstadt, Germany). The solution was diluted to $5 \mathrm{ml}$ with distilled water and allowed to stand for 30 minutes and a change in color (red-blue) was observed. The protocol was applied to 5 standard solutions of PCA between $0.0005 \%$ and $0.001 \%$, absorbance was read in the visible range $(350-800 \mathrm{~nm})$ to determine $\lambda$ max and the calibration curve was constructed.

The maximum lambda $(\lambda \max )$ for $\mathrm{NaOCI}$, EDTA, CHX and PCA are shown in Table $\mathrm{N}^{\circ} 1$

Table $\mathrm{N}^{\circ}$ 1: The maximum lambda (Imax) for $\mathrm{NaOCl}$, EDTA, $\mathrm{CHX}$ and PCA

\begin{tabular}{|c|c|c|c|c|}
\hline \multicolumn{1}{c|}{} & $\mathrm{NaOCl}$ & EDTA & CHX & PCA \\
\hline$\lambda \mathrm{max}$ & $290 \mathrm{~nm}$ & $207 \mathrm{~nm}$ & $255 \mathrm{~nm}$ & $552 \mathrm{~nm}$ \\
\hline
\end{tabular}

\section{STATISTICAL ANALYSIS.}

Average concentrations of $\mathrm{NaOCl}$, EDTA, $\mathrm{CHX}$ and PCA in all endodontic treatment phases were calculated and their minimum, maximum and standard deviations were calculated.

\section{RESULTS}

Concentration of $\mathrm{NaOCl}$ and EDTA: Using calibration curves, $\lambda$ max and sample absorbance, the concentration of $\mathrm{NaOCl}$ and EDTA was calculated at different stages of the proposed endodontic treatment protocol (Figure $\mathrm{N}^{\circ} 1$ ).

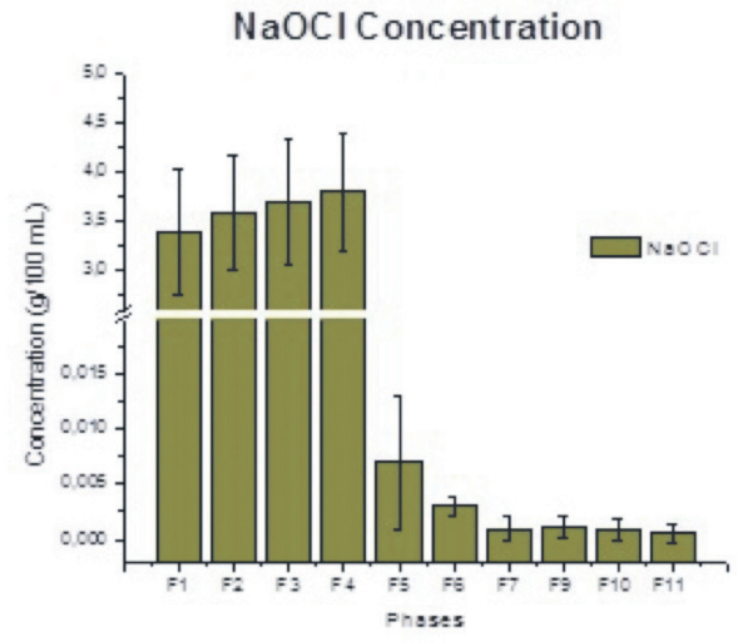

Figure 1. $\mathrm{NaOCl}$ concentration during chemical-mechanical preparation (F1- F4) and the elutions with $0.9 \% \mathrm{NaCl}(\mathrm{F} 5-\mathrm{F} 11)$

$5 \% \mathrm{NaOCl}$ was used in the first four phases (F1 to F4) of chemicalmechanical preparation root canal. $\mathrm{NaOCl}$ concentration decreased from $5 \%$ to $3.4 \%$ in $\mathrm{F} 1,3.6 \%$ in $\mathrm{F} 2,3.7 \%$ in $\mathrm{F} 3$ and to $3.8 \%$ in $\mathrm{F} 4$. In phases 5 6 and 7 , irrigation with $0.9 \% \mathrm{NaCl}$ was used, and the average values of $\mathrm{NaOCl}$ concentrations were $0.007 \%, 0.003 \%$ and $0.001 \%$, respectively. In phases 9, 10 and 11, the canal was irrigated again with saline and the $\mathrm{NaOCl}$ concentration was measured with average values of $0.0011 \%$, $0.0009 \%$ and $0.0006 \%$.

In phase 8 , the irrigant used was $10 \%$ EDTA and its final average concentration was $8.9 \%$. In phases 9,10 and 11 , after irrigation with saline, EDTA concentrations were determined with average values of $0.013 \%, 0.006 \%$ and $0.002 \%$ (Figure $N^{\circ} 2$ ).

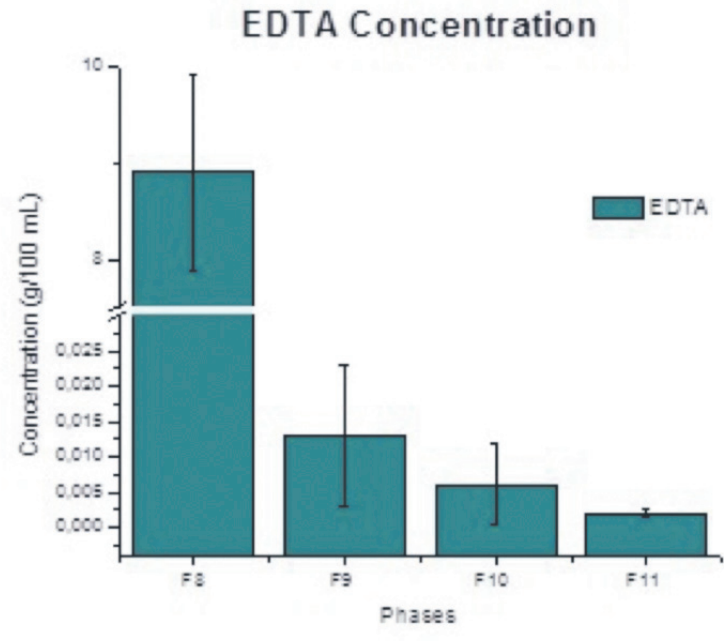

Figure 2. EDTA concentration in phase 8 (F8) of endodontic treatment and during the elutions with $0.9 \% \mathrm{NaCl}$. (F9 - F11)

CHX and PCA concentration: Phases 12 and 13 used 2\% $\mathrm{CHX}$ as intracanal medication and prior to sealing the canal. The average concentrations of $\mathrm{CHX}$ found in $\mathrm{F} 12$ were $1.85 \%$ and $1.80 \%$ in $\mathrm{F} 13$. For $\mathrm{PCA}$, average values were $0.0007 \%$ in $\mathrm{F} 12$ and $0.0005 \%$ in $\mathrm{F} 13$. (Figure $\mathrm{N}^{\circ} 3$ ). PCA formation from $2 \% \mathrm{CHX}$ : It has been described that $\mathrm{CHX}$ can be hydrolyzed to PCA spontaneously in the presence of heat, light and alkaline environments. To determine the possible contribution of PCA from $\mathrm{CHX}$, we analyzed the $2 \% \mathrm{CHX}$ solution used for irrigation and 
established an average concentration of $0.0002 \%$ PCA. We saw (Figure 4) that the absorption curves for samples F12 and F13 have more intense peaks of PCA than the one observed in the $2 \% \mathrm{CHX}$ curve.

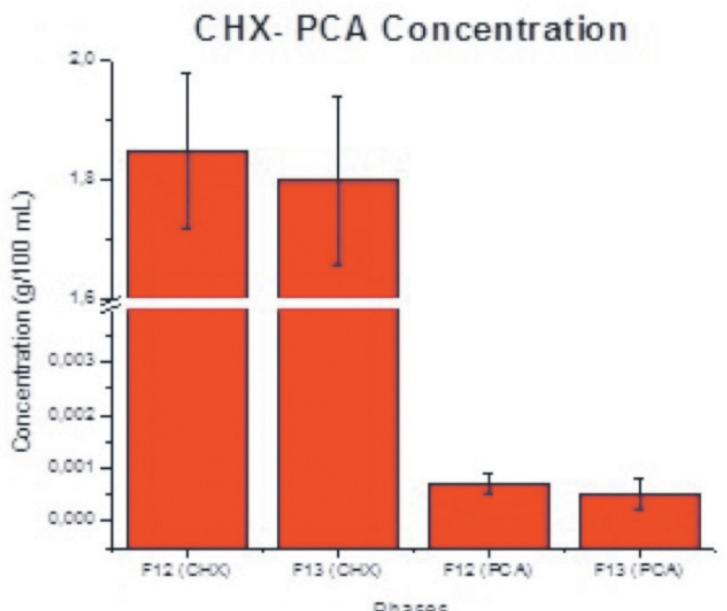

Figure 3. $\mathrm{CHX}$ and PCA concentration in phases 12 and 13 of endodontic treatment.

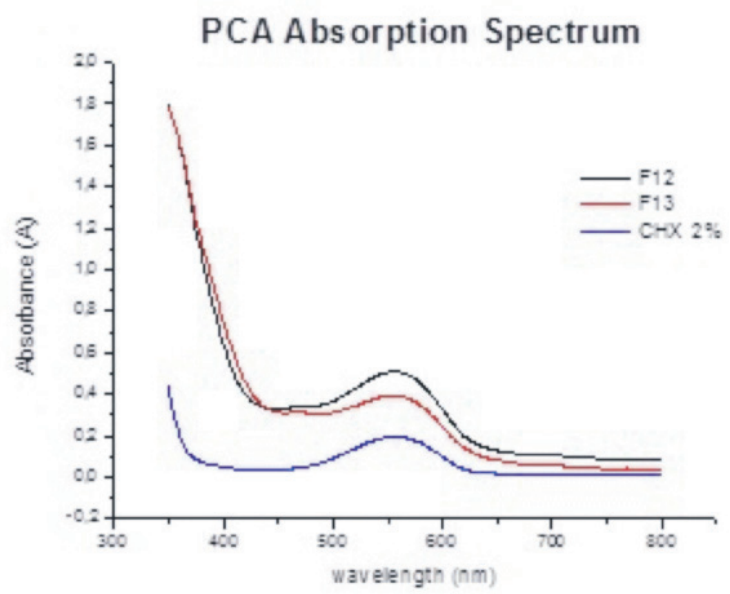

Figure 4. PCA absorption spectrum of phases 12 and 13 (F12 and F13) and from the $2 \% \mathrm{CHX}$ solution.

\section{DISCUSSION}

The irrigation protocol proposed in this study used different irrigants in a specific sequence and concentration, to boost the main features of each root canal irrigant and also to avoid the formation of PCA. Irrigation with $5 \% \mathrm{NaOCl}$ was used during the chemomechanical preparation of the canal because of antimicrobial activity for the dissolution of the organic component and necrotic tissue present in the root canal ${ }^{(4,5)}$. Then, the canal was irrigated with saline to dilute the $\mathrm{NaOCl}$. We used EDTA at $10 \%$ and allowed it to act for 1 minute to remove the smear layer caused by instrumentation ${ }^{(11)}$. The canal was once again washed with saline to dilute the EDTA and $\mathrm{NaOCl}$ remanents. Finally, we used $2 \% \mathrm{CHX}$ as intracanal medication and prior to RCO, due to its broad antibacterial spectrum and substantivity ${ }^{(1)}$.

In this study, the concentration of $\mathrm{NaOCl}$ was determined during early stages of root canal preparation and we observed that the initial concentration of $5 \%$ decreases to average values of $3.4 \%$ in the first stage (access cavity) and to $3.8 \%$ in the fourth step (Step-Back). This is explained by the higher percentage of organic matter in the early stages of the process. $\mathrm{NaOCl}$ inactivation when interact with organic matter has been described in previous studies, when antibacteria activity was measured after contact with the dentine ${ }^{(12)}$. This inactivation is caused when the $\mathrm{NaOCl}$ makes contact with organic matter, because of saponification and neutralization reactions, which occur mainly on the contact surface between $\mathrm{NaOCl}$ and organic matter, leading to organic tissue liquefaction ${ }^{(13)}$. At the same time, $\mathrm{NaOCl}$ molecules are consumed, resulting in a decrease concentration and local activity ${ }^{(14)}$.

Several studies have analyzed the interaction between $\mathrm{NaOCl}$ and $\mathrm{CHX}$ and found mixed results; while some have ruled out the presence of $\mathrm{PCA}^{(8,15)}$, others have demonstrated the formation of a brown-orange precipitate when $\mathrm{NaOCl}$ and $\mathrm{CHX}$ solutions are mixed, in addition to the presence of PCA in the precipitate ${ }^{(7,16-19)}$. These differences could be due to the varied methodologies used in the studies. Because of cytotoxicity in rats and the carcinogenic potential of PCA in humans (World Health Organization, 2006)(10), it is important to evaluate different intermediate irrigation protocols to prevent formation.

The irrigation protocol uses saline to dilute the $\mathrm{NaOCl}$ which may be in the root canals in phases 5,6 and 7 . The results show a significant decrease in the concentration of $\mathrm{NaOCl}(0.007 \%$ to $0.001 \%)$, but studies have shown that mixing $2 \% \mathrm{CHX}$ with $\mathrm{NaOCl}$ aqueous dilutions ranging from $5 \%$ to $0.0005 \%$ produces a color change directly related to the concentration of $\mathrm{NaOCl}$, showing the formation of PCA, which corresponds to results obtained by Basrani et al. ${ }^{(7)}$ and Gasic et al. ${ }^{(20)}$.

The concentration of 10\% EDTA, after passing through the root canal, decreases significantly to an average of $8.9 \%$, due to the chelating ability of its $\mathrm{Ca}^{2+}$ ions on dentine, causing demineralization in peri and intertubular dentine and a smear layer during the time that it is in contact with the root canal walls. EDTA has also been used as an intermediate irrigant for washing and inactivates $\mathrm{NaOCl}$ present in the dentinal tubules, avoiding the formation of PCA, but like in our results, the presence of PCA was also found after using $2 \% \mathrm{CHX}^{(21)}$.

In phases $9,10,11$, we used $0.9 \% \mathrm{NaCl}$ in the irrigation protocol, mainly to remove EDTA present in the root canal. The average values indicate EDTA concentrations from $0.013 \%$ to $0.002 \%$. The use of $\mathrm{NaCl}$ $0.9 \%$ in high volumes for intermediate irrigation is shown to be effective in diluting the presence of $\mathrm{NaOCl}$ and EDTA in the root canal, decreasing concentrations prior to the use of $\mathrm{CHX} 2 \%$, but does not prevent PCA formation. This can be confirmed because in phases F9, F10 and F11, $\mathrm{NaOCl}$ could be quantified at average concentrations ranging from $0.0011 \%$ to $0.0006 \%$, lower values, but enough to form PCA in the presence of $2 \% \mathrm{CHX}$. This was previously demonstrated in an in vitro study where the influence of $\mathrm{NaCl} 0.9 \%$, between $5 \% \mathrm{NaOCl}$ and $2 \% \mathrm{CHX}$, was evaluated, proving that $\mathrm{NaCl} 0,9 \%$ cannot prevent the formation of $\mathrm{PCA}^{(22)}$.

In Phases 12 and 13, we used 2\% CHX solution as irrigant and intracanal medication, due to its substantivity and broad antibacterial spectrum $^{(1)}$, and the final concentration was less than $2 \%(1.85 \%$ in phase 12 and $1.8 \%$ in phase 13). This lower concentration could be explained by $\mathrm{CHX}$ substantivity, capability of binding to the dentin through electrostatic interaction. Perhaps in an in vivo situation this drop would be greater, because of the presence of more microorganisms or organic tissue in the root canal.

In this study, we determined the concentration of PCA using the modified protocol of the European Pharmacopoeia (2005)(10), for the detection of $\mathrm{p}$-chloroaniline in chlorhexidine digluconate solution. PCA presence was established in the late phases (F12 and F13), after irrigation with $2 \% \mathrm{CHX}$, with average concentrations of PCA in the order of $10^{-3}$ to $10^{-4} \mathrm{~g} / 100 \mathrm{ml}$

Various studies have evaluated the formation of PCA after using different irrigating solutions between $\mathrm{NaOCl}$ and $\mathrm{CHX}$. For example, they used citric acid or saline ${ }^{(21)}$ isopropyl alcohol, saline and distilled water ${ }^{(19)}$ to prevent the formation of PCA, but only isopropyl alcohol had a preventive action. This is because it is a surfactant agent, which is volatile and highly electronegative and may penetrate better into the root canal to remove residual $\mathrm{NaOCl}$. However, its biocompatibility with periapical tissues has not been fully studied. The irrigation protocol used in this study differs from previous studies, but we also found residual PCA because EDTA and $0.9 \% \mathrm{NaCl}$ fail to fully penetrate into the root canal or dentinal tubules to inactivate or drag $\mathrm{NaOCl}$ totally.

This study showed that $2 \% \mathrm{CHX}$ solution contains low levels of PCA; this suggests that, as reported previously, $\mathrm{CHX}$ in aqueous solution slowly hydrolyzes and forms p-chloroaniline (PCA). PCA has been detected in $2 \%$ $\mathrm{CHX}$ solutions, stored at $36,5^{\circ} \mathrm{C}$ and $95 \%$ relative humidity, immediately and increased 7 days after preparation ${ }^{(23)}$. Our results suggest that when $\mathrm{NaOCl}$ is mixed with $\mathrm{CHX}$, the $\mathrm{CHX}$ molecule is hydrolyzed into small parts, forming subproducts. The first broken link in the reaction is between carbon and nitrogen, due to low energy dissociation between these two atoms, which would produce dissociation and the formation of PCA among other fragments ${ }^{(7,19)}$.

\section{CONCLUSION}

UV-VISIBLE methodology allows us to measure $\mathrm{NaOCI}$, EDTA, CHX and PCA during the endodontic irrigation protocol. $5 \% \mathrm{NaOCl}$ decreases 
its concentration and local activity significantly during the first four phases due to the effect of the root canal preparation. $\mathrm{NaOCl}$ is also detected in phases 5, 6, 7, 9, 10 and 11 at minor but measurable concentrations. $10 \%$ EDTA in phase 8 decreases due to its action on the smear layer, and is measurable in stages 9,10 and 11. $2 \% \mathrm{CHX}$ decreases after intracanal use, possibly due to interaction with root canal dentin. PCA formation occurs in canals in the presence of $2 \% \mathrm{CHX}$ and $\mathrm{NaOCl}$, and was detected in phases 12 and 13.

\section{Reference}

1. Zehnder M. Root canal irrigants. J Endod. 2006; 32(5):389-98.

2. Haapasalo M, Shen Y, Qian W , Gao Y. Irrigation in endodontics. Dent Clin North Am. 2010; 54(2):291-312

3. Beltz RE, Torabinejad M ,Pouresmail M. Quantitative analysis of the solubilizing action of MTAD, sodium hypochlorite, and EDTA on bovine pulp and dentin. J Endod. 2003; 29(5):334-7.

4. Gomes BP, Ferraz CC, Vianna ME, Berber VB, Teixeira FB ,Souza-Filho FJ. In vitro antimicrobial activity of several concentrations of sodium hypochlorite and chlorhexidine gluconate in the elimination of Enterococcus faecalis. Int Endod J. 2001; 34(6):424-8.

5. Vianna ME, Gomes BP, Berber VB, Zaia AA, Ferraz CC , de Souza-Filho FJ. In vitro evaluation of the antimicrobial activity of chlorhexidine and sodium hypochlorite. Oral Surg Oral Med Oral Pathol Oral Radiol Endod. 2004; 97(1):79-84.

6 . Basrani B ,Haapasalo M. Update on endodontic irrigating solutions. Endodontic Topics. 2016; 27(1):74-102.

7. Basrani BR, Manek S, Sodhi RN, Fillery E , Manzur A. Interaction between sodium hypochlorite and chlorhexidine gluconate. J Endod. 2007; 33(8):966-9.

8. Prado M, Santos Junior HM, Rezende CM, Pinto AC, Faria RB, Simao RA, et al Interactions between irrigants commonly used in endodontic practice: a chemical analysis. J Endod. 2013; 39(4):505-10.

9. Boehncke A, Kielhorn J, Könnecker G, Pohlenz-Michel C ,Mangelsdorf I. Concise International Chemical Assessment Document 48 4-CHLOROANILINE. 2003.

10. C. EPM. Solution chlorhexidine digluconate. 5th Edition. 2005.

11. Calt S ,Serper A. Time-dependent effects of EDTA on dentin structures. J Endod. 2002; 28(1):17-9.

12. Haapasalo HK, Siren EK, Waltimo TM, Orstavik D ,Haapasalo MP. Inactivation of local root canal medicaments by dentine: an in vitro study. Int Endod J. 2000; 33(2):126-31.

13. Estrela C, Estrela CR, Barbin EL, Spano JC, Marchesan MA ,Pecora JD Mechanism of action of sodium hypochlorite. Braz Dent J. 2002; 13(2):113-7.
14. Stojicic S, Zivkovic S, Qian W, Zhang H ,Haapasalo M. Tissue dissolution by sodium hypochlorite: effect of concentration, temperature, agitation, and surfactant. J Endod. 2010; 36(9):1558-62.

15. Nowicki JB ,Sem DS. An In Vitro Spectroscopic Analysis to Determine the Chemical Composition of the Precipitate Formed by Mixing Sodium Hypochlorite and Chlorhexidine. J Endod. 2011; 37(7):983-8.

16. Basrani BR, Manek S ,Fillery E. Using diazotization to characterize the effect of heat or sodium hypochlorite on 2.0\% chlorhexidine. J Endod. 2009; 35(9):1296-9.

17. Basrani BR, Manek S, Mathers D, Fillery E, Sodhi RN. Determination of 4-chloroaniline and its derivatives formed in the interaction of sodium hypochlorite and chlorhexidine by using gas chromatography. J Endod. 2010; 36(2):312-4

18. Bui TB, Baumgartner JC, Mitchell JC. Evaluation of the interaction between sodium hypochlorite and chlorhexidine gluconate and its effect on root dentin. J Endod. 2008; 34(2):181-5.

19. Krishnamurthy $S$, Sudhakaran S. Evaluation and prevention of the precipitate formed on interaction between sodium hypochlorite and chlorhexidine. J Endod. 2010; 36(7):1154-7.

20. Gasic J, Popovic J, Zivković S, Petrovic A, Barac R, Nikolic M. Ultrastructural analysis of the root canal walls after simultaneous irrigation of different sodium hypochlorite concentration and 0.2\% chlorhexidine gluconate. Microsc Res Tech. 2012;75(8):1099-103 21. Mortenson D, Sadilek M, Flake NM, Paranjpe A, Heling I, Johnson JD, et al. The effect of using an alternative irrigant between sodium hypochlorite and chlorhexidine to prevent the formation of para-chloroaniline within the root canal system. Int Endod J. 2012; 45(9):878-82.

22. Bilbao Bravo MC. Influencia del suero fisiológico en la formación de paracloroanilina, estudio in vitro. [Tesis] Universidad de Chile, 2013

23. Barbin LE, Estrela C, Guedes DF, Spano JC, Sousa-Neto MD ,Pecora JD. Detection of para-chloroaniline, reactive oxygen species, and 1-chloro-4nitrobenzene in high concentrations of chlorhexidine and in a mixture of chlorhexidine and calcium hydroxide. J Endod. 2013; 39(5):664-8. 